\title{
Comparison of values of CT and MRI imaging in the diagnosis of hepatocellular carcinoma and analysis of prognostic factors
}

\author{
GUIBIN WANG ${ }^{1}$, SHICAI ZHU ${ }^{2}$ and XIUKUI LI $^{3}$ \\ ${ }^{1}$ Department of Imaging, Linyi People's Hospital, Linyi, Shandong 276003; \\ ${ }^{2}$ Department of Imaging, Linyi Thoracic Hospital, Linyi, Shandong 276002; \\ ${ }^{3}$ Department of Imaging, Linyi Cancer Hospital, Linyi, Shandong 276001, P.R. China
}

Received April 20, 2018; Accepted October 25, 2018

DOI: $10.3892 / 01.2018 .9690$

\begin{abstract}
Value of computed tomography (CT) and magnetic resonance imaging (MRI) in the diagnosis of small hepatocellular carcinoma (HCC), and in analysis of the prognostic factors of primary hepatocellular carcinoma (PHC) were compared. A total of 300 patients with PHC were selected from January 2013 to January 2016. Among them, 170 patients were diagnosed with small HCC. Patients were diagnosed by MRI and CT scans, respectively, and diagnostic efficacy of the methods was compared. A single factor and multivariate analysis of prognostic factors were performed on 300 patients. The sensitivity of MRI screening was $78.82 \%$, specificity was $78.46 \%$, accuracy was $78.67 \%$, positive predictive value was $82.72 \%$, and negative predictive value was $73.91 \%$. CT screening showed a sensitivity of $62.35 \%$, a specificity of $73.85 \%$, an accuracy of $67.33 \%$, a positive predictive value of $75.71 \%$, and a negative predictive value of $60.00 \%$. Differences in sensitivity, accuracy, and negative predictive value between MRI and CT screening were statistically significant $(\mathrm{P}<0.05)$. There was no statistically significant difference between two groups in specificity and positive predictive value $(\mathrm{P}>0.05)$. Diagnostic efficiency of MRI is better than that of CT diagnosis. Univariate analysis showed that age, hepatitis B cirrhosis background, tumor stage, and portal vein embolization were prognostic factors for PHC. Cox multivariate regression analysis showed that the background of liver cirrhosis, tumor stage, and portal thrombosis were independent risk factors for poor prognosis for PHC patient and the differences were statistically significant $(\mathrm{P}<0.05)$. MRI is superior to $\mathrm{CT}$ in the sensitivity, specificity and accuracy of the diagnosis of small HCC. Individualized comprehensive treatment plans based on the patient's condition may be effective in prolonging the
\end{abstract}

Correspondence to: Dr Xiukui Li, Department of Imaging, Linyi Cancer Hospital, 6 Lingyuan Dong Street, Lanshan, Linyi, Shandong 276001, P.R. China

E-mail: xz26c5@163.com

Key words: MRI, CT, primary hepatocellular carcinoma, small hepatocellular carcinoma, diagnostic value, prognosis patient's survival time. Imaging diagnosis can provide survival basis for patients, improve diagnostic accuracy, and help to improve the survival rate.

\section{Introduction}

Hepatocellular carcinoma (HCC) is the fifth most common malignant tumor, and its mortality ranks third among all malignancies. HCC affects 620,000 new patients and causes 600,000 deaths every year posing a serious threat to people's health (1). Nearly half of patients with primary hepatocellular carcinoma (PHC) die due to lymph node metastasis (2). At present, $90 \%$ of $\mathrm{PHC}$ is developed from hepatitis and liver cirrhosis, and the risk of $\mathrm{PHC}$ is even greater after infection with hepatitis B and C (3). Cirrhosis also has a 35\% risk of malignant transformation (4). Other causes of chronic liver injury include alcoholism, cholestasis, metabolic disorders, autoimmune and steatohepatitis $(5,6)$. Due to the lack of obvious clinical features in early stage of HCC, most patients miss the best treatment time by the time of diagnosis, leading to a poor prognosis because of the high degree of malignancy and metastasis caused by HCC (7).

In recent years, imaging techniques have been continuously developed, and it is very important to be familiar with the characteristics and advantages of different imaging methods. It is of great significance to select appropriate imaging examination methods according to patient's pathological conditions to improve the early diagnosis of HCC and improve patients' survival. Therefore, the diagnosis of small HCC has become a hot topic in recent years (8-11). Small HCC is defined as a single tumor nodule with a diameter $\leq 3 \mathrm{~cm}(12,13)$. The most commonly used imaging methods for diagnosing $\mathrm{HCC}$ in clinical practice are computed tomography (CT) and magnetic resonance imaging (MRI) (14). Compared with CT, MRI is more complex. Each sequence has a different organizationcontrast mechanism, and each sequence is irreplaceable. MRI can provide liver anatomy images and information about patients' physiological and metabolic function $(15,16)$. However, MRI examinations are expensive, scan time is long and there are contraindications for patients. Therefore, MRI examinations are often used as supplementary means for CT examinations. The purpose of this study was to analyze the diagnostic value of CT and MRI examinations for small 
$\mathrm{HCC}$ in patients, and to analyze the prognostic factors of $\mathrm{PHC}$ patients.

\section{Materials and methods}

General information. This study is a retrospective analysis. A total of 300 patients with HCC who were treated in Linyi People's Hospital (Linyi, China) from January 2013 to January 2016 were selected as the study subjects. There were 186 males and 114 females, and the mean age was $43.46 \pm 13.14$ years. Among them, 170 were diagnosed as small HCC patients by biopsy or postoperative pathological examinations. Before CT or MRI examination, patients did not receive interventional therapy or related liver surgery. All the patients were excluded from pregnancy, blood system diseases, hypotension drugs, abdominal surgery history, and other types of tumors and metastases. The patients had complete clinical, pathological and surgical records. The study was approved by the Ethics Commitee of Linyi People's Hospital. Patients who participated in this research, signed the informed consent and had complete clinical data. General information is listed in Table I.

Equipment. The 64-slice spiral CT was purchased from Siemens Healthineers (Erlangen, Germany). The 3.0 Tesla MRI was purchased from GE Healthcare (Chicago, IL, USA). Iohexol contrast agent was purchased from Guangzhou Schering Pharmaceutical Co., Ltd. (Guangzhou, China). Gd-DTPA contrast agent was purchased from GE Healthcare.

MRI examination. Patients were fasted for more than $4 \mathrm{~h}$ before examination. Scanning was performed after inhaling. Patients were fixed in supine position. In routine examination, spin-echo sequences were used for transverse axis T1-weighted images, T2-weighted images, diffusion-weighted images, gradient echoes, antiphase, fast volumetric plain scans, respiratory gating and breathhold scans, with a slice thickness of $6 \mathrm{~mm}$. Gd-DTPA was used as a contrast agent during enhanced scan and was injected via forearm superficial vein at a rate of $2.5 \mathrm{ml} / \mathrm{sec}$ using a high-pressure syringe. Arterial phase was scanned for $10 \mathrm{sec}$, portal vein phase was scanned for $5 \mathrm{sec}$, and equilibrium phase was scanned for $90 \mathrm{sec}$.

The 64-slice spiral CT examination. Patients were fasted for more than $8 \mathrm{~h}$ before examination, and 800-1,000 $\mathrm{ml}$ of warm water was used to inflate the intestines $30 \mathrm{~min}$ before scan. Breathing was performed and scanning was started after inhaling. Scanning layer's thickness was $5 \mathrm{~mm}$. Iohexol contrast agent was injected at a speed of $3 \mathrm{ml} / \mathrm{sec}$ for enhanced scan. Arterial phase scan was performed for 25-30 sec, portal vein phase scan was performed $60-70 \mathrm{sec}$, balance phase scan was performed for $120-180 \mathrm{sec}$.

Diagnostic analysis. Image analysis was performed by two imaging physicians with $>10$ years' experience in the field and AFP examination was combined to confirm the diagnosis of small HCC. Diagnostic efficacy of the two imaging methods was evaluated based on sensitivity, specificity, accuracy, positive predictive value, and negative predictive value.
Table I. General information.

\begin{tabular}{lrc}
\hline Factors & $\mathrm{n}$ & Ratio (\%) \\
\hline Age & & \\
$\geq 43$ & 206 & 68.67 \\
$<43$ & 94 & 31.33 \\
Sex & & \\
Male & 186 & 62.00 \\
Female & 114 & 38.00 \\
Tumor stage & & \\
I+II & 208 & 69.33 \\
III+IV & 92 & 30.67
\end{tabular}

Hepatitis B,

cirrhosis background

Yes 198

66.00

No

102

34.00

Liver function grading

A

137

45.67

B

31.33

C

23.00

Tumor typing

Massive type 43

14.33

Nodularity $\quad 224$

74.67

Diffuse type

11.00

Portal embolism

Yes 41

13.67

No

259

86.33

Alcohol consumption

Do not drink 85

Occasionally

Regular drinking

39.33

Tumor distribution

Left liver lobe $\quad 94$

31.33

Right liver lobe $\quad 134$

44.67

Left and right liver leaves

24.00

Statistical analysis. SPSS 17.0 (SPSS, Inc., Chicago, IL, USA) was used for statistical analysis. $\chi^{2}$ test was used for analysis of count data. Kaplan-Meier method was used for univariate survival analysis. Cox proportional hazards model was used for multifactorial analysis. $\mathrm{P}<0.05$ was considered to indicate a statistically significant difference.

\section{Result}

Diagnosis analysis. MRI detected 134 cases of true positive small HCC, and the accuracy was 78.67\%. In addition, 106 cases of true small HCC were detected by $\mathrm{CT}$ and the accuracy rate was $67.33 \%$. CT scan is insensitive for the diagnosis of small $\mathrm{HCC}$, and imaging of adjacent tissues is not clear, which may cause misdiagnosis and diagnostic errors. Thirteen patients were negative by CT screening and were positive after MRI screening and were confirmed as positive by pathological analysis. 
Table II. Comparison of MRI scan results with pathological examination results.

\begin{tabular}{lccc}
\hline & \multicolumn{2}{c}{ MRI } & \\
\cline { 2 - 3 } $\begin{array}{l}\text { Pathological } \\
\text { examination results }\end{array}$ & Small HCC & Other types & Total \\
\hline Small HCC & 134 & 36 & 170 \\
Other types & 28 & 102 & 130 \\
Total & 162 & 138 & 300 \\
\hline
\end{tabular}

MRI, magnetic resonance imaging; HCC, hepatocellular carcinoma.

Table III. Comparison of CT scan results with pathological examination results.

\begin{tabular}{lccc}
\hline & \multicolumn{3}{c}{ CT } \\
\cline { 2 - 3 } $\begin{array}{l}\text { Pathological } \\
\text { examination results }\end{array}$ & Small HCC & Other types & Total \\
\hline Small HCC & 106 & 64 & 170 \\
Other types & 34 & 96 & 130 \\
Total & 140 & 160 & 300 \\
\hline
\end{tabular}

$\mathrm{CT}$, computed tomography; HCC, hepatocellular carcinoma.

Table IV. Comparison of the efficacy of MRI and CT in the diagnosis of small HCC (\%).

\begin{tabular}{|c|c|c|c|c|c|c|}
\hline Groups & $\mathrm{n}$ & Sensitivity & Specificity & Accuracy & $\begin{array}{c}\text { Positive } \\
\text { predictive } \\
\text { value }\end{array}$ & $\begin{array}{c}\text { Negative } \\
\text { predictive } \\
\text { value }\end{array}$ \\
\hline MRI & 300 & 78.82 & 78.46 & 78.67 & 82.72 & 73.91 \\
\hline $\mathrm{CT}$ & 300 & 62.35 & 73.85 & 67.33 & 75.71 & 60.00 \\
\hline$\chi^{2}$ & & 11.11 & 0.763 & 9.775 & 2.257 & 6.433 \\
\hline P-value & & 0.001 & 0.383 & 0.002 & 0.133 & 0.011 \\
\hline
\end{tabular}

MRI, magnetic resonance imaging; CT, computed tomography; HCC, hepatocellular carcinoma.

Comparison of diagnostic efficacy of MRI and CT on small $H C C$. MRI screening showed a sensitivity of $78.82 \%$, a specificity of $78.46 \%$, an accuracy of $78.67 \%$, a positive predictive value of $82.72 \%$, and a negative predictive value of $73.91 \%$. CT screening showed a sensitivity of $62.35 \%$, a specificity of $73.85 \%$, an accuracy of $67.33 \%$, a positive predictive value of $75.71 \%$, and a negative predictive value of $60.00 \%$. Differences in sensitivity, accuracy, and negative predictive value between MRI and CT screening were statistically significant $(\mathrm{P}<0.05)$. There was no statistically significant differences between two methods in specificity and positive predictive value $(\mathrm{P}>0.05)$ (Tables II-IV).

Analysis of influencing factors of patient survival time. Univariate analysis of survival factors in 300 patients showed
Table V. Results of single factor analysis of prognosis of PHC patients.

\begin{tabular}{|c|c|c|c|}
\hline Items & P-value & HR & $\begin{array}{l}95 \% \\
\text { confidence } \\
\text { interval }\end{array}$ \\
\hline $\begin{array}{l}\text { Sex } \\
\text { (male vs. female) }\end{array}$ & 0.485 & 1.062 & $0.523-1.946$ \\
\hline $\begin{array}{l}\text { Age } \\
(<43 \text { vs. } \geq 43 \text { years })\end{array}$ & 0.043 & 3.765 & $2.346-4.427$ \\
\hline $\begin{array}{l}\text { Hepatitis B cirrhosis } \\
\text { background (yes vs. no) }\end{array}$ & 0.013 & 0.436 & $0.356-0.821$ \\
\hline $\begin{array}{l}\text { Liver function grading } \\
\text { (A vs. B vs. C) }\end{array}$ & 0.232 & 3.518 & $1.265-4.124$ \\
\hline $\begin{array}{l}\text { Tumor staging } \\
\text { (I, II vs. III, IV) }\end{array}$ & 0.024 & 2.341 & $1.834-2.701$ \\
\hline $\begin{array}{l}\text { Tumor tissues } \\
\text { (Massive type vs. } \\
\text { nodularity vs. diffuse type) }\end{array}$ & 0.064 & 2.746 & $1.868-4.103$ \\
\hline $\begin{array}{l}\text { Portal embolism } \\
\text { (yes vs. no) }\end{array}$ & 0.032 & 0.689 & $0.535-0.912$ \\
\hline
\end{tabular}

Table VI. Results of multivariate analysis of PHC prognosis.

\begin{tabular}{lccc}
\hline & P-value & HR & $\begin{array}{c}95 \% \\
\text { confidence } \\
\text { interval }\end{array}$ \\
\hline $\begin{array}{l}\text { Items } \\
\begin{array}{l}\text { Age } \\
(<43 \text { vs. } \geq 43 \text { years) }\end{array}\end{array}$ & 1.032 & 4.029 & $2.306-6.082$ \\
$\begin{array}{l}\text { Hepatitis B cirrhosis } \\
\text { background (yes vs. no) }\end{array}$ & 0.021 & 0.469 & $0.314-0.672$ \\
$\begin{array}{l}\text { Tumor staging } \\
\text { (I, II vs. III, IV) }\end{array}$ & 0.016 & 2.327 & $1.876-2.728$ \\
$\begin{array}{l}\text { Portal embolism } \\
\text { (yes vs. no) }\end{array}$ & 0.018 & 0.681 & $0.512-0.908$ \\
\hline
\end{tabular}

PHC, primary hepatocellular carcinoma.

that adverse factors that affect the prognosis of patients with HCC include age, hepatitis B cirrhosis background, tumor stage and portal vein embolism. The differences were statistically significant $(\mathrm{P}<0.05)$. Cox multivariate regression analysis showed that the background of liver cirrhosis, tumor stage, and portal thrombosis were independent risk factors for poor prognosis of cancer. The differences were statistically significant $(\mathrm{P}<0.05)($ Tables V and VI).

\section{Discussion}

The main functions of liver are metabolism and blood supply. Occurrence and development of primary HCC are complex, and its early diagnosis has important significance in improving the prognosis and quality of life of patients (17). MRI and CT scans 
are clinically important screening methods for diagnosing liver cancer, and can provide detailed parameters for specific tumor conditions. It has been reported that an important factor in the diagnosis and evaluation of postoperative clinical efficacy is the detection rate of small HCC (18). Because of the high cost, combination of MRI and CT has not been popularized in clinical application. MRI and CT have their own advantages and disadvantages in clinical applications, and application of single technique may cause misdiagnosis or diagnostic errors. For screening of small HCC, diagnostic accuracy of MRI is higher than that of CT scan (19-21). Therefore, in the actual clinical application, patient's condition should be combined to improve diagnostic efficiency. Patients who are at risk but do not have obvious symptoms should be checked regularly to increase the early diagnosis rate and improve therapeutic effects.

This study showed that MRI reached screening sensitivity of $78.82 \%$, specificity of $78.46 \%$, accuracy of $78.67 \%$, positive predictive value of $82.72 \%$ and negative predictive value of $73.91 \%$. CT screening showed a sensitivity of $62.35 \%$, a specificity of $73.85 \%$, an accuracy of $67.33 \%$, a positive predictive value of $75.71 \%$, and a negative predictive value of $60.00 \%$. Differences in sensitivity, accuracy, and negative predictive value between MRI and CT screening were statistically significant $(\mathrm{P}<0.05)$. There was no statistically significant difference between two methods in specificity and positive predictive value $(\mathrm{P}>0.05)$. The diagnostic performance of MRI is better than that of CT. Consistent findings were found in the study reported by Hwang et al (22). Although CT scan technology has high temporal and spatial resolution, it has limitations in the screening of small HCC. Differences in tumor lesions and uneven liver density, CT may not be active in the diagnosis of small HCC (23). Univariate analysis showed that factors affects the prognosis of patients with HCC included age, background of hepatitis B cirrhosis, tumor stage, and portal thrombosis. Cox multivariate regression analysis showed that background of liver cirrhosis, tumor staging, and portal vein embolization were risk factors for the prognosis of HCC and the differences were statistically significant $(\mathrm{P}<0.05)$. McNally et al $(24)$ also reported that cirrhosis, tumor staging, and portal thrombosis were independent risk factors for poor prognosis of HCC. Liver cirrhosis causes changes in the microenvironment of the liver, resulting in circulation of hepatoma cells and the emergence of new lesions. The number, size, degree of infiltration, and metastasis of tumors are all related to tumor stage, and have an impact on the survival of patients. If portal embolism affects normal blood supply to the liver, tumor may spread via the portal route $(25)$.

In conclusion, the diagnostic efficacy of MRI in the diagnosis of small HCC is better than that of CT scan screening. When CT screening is not sufficient to accurately determine liver tumor lesions, MRI can provide a more precise imaging basis. Univariate and Cox multivariate regression analysis showed that the background of hepatitis B liver cirrhosis, tumor staging, and portal vein embolization were independent risk factors for poor prognosis of HCC. Therefore, developing individualized comprehensive treatment programs based on different situations of patients, regularly reviewing and timely taking measures for complications may effectively prolong the survival of patients. Thus, within the affordable scope of medical expenses, MRI diagnosis can provide important basis and screening method for appropriate treatment of HCC.

\section{Acknowlwedgements}

Not applicable.

\section{Funding}

No funding was received.

\section{Availability of data and materials}

The datasets used and/or analyzed during the present study are available from the corresponding author on reasonable request.

\section{Authors' contributions}

GW designed this study and wrote the manuscript. GW and SZ were responsible for MRI examination. XL interpreted CT results. All authors read and approved the final study.

\section{Ethics approval and consent to participate}

The study was approved by the Ethics Committee of Linyi People's Hospital (Linyi, China). Patients who participated in this research, signed the informed consent and had complete clinical data.

\section{Patient consent for publication}

Not applicable.

\section{Competing interests}

The authors declare that they have no competing interests.

\section{References}

1. Center MM and Jemal A: International trends in liver cancer incidence rates. Cancer Epidemiol Biomarkers Prev 20: 2362-2368, 2011

2. Mosher CE, Johnson C, Dickler M, Norton L, Massie MJ and DuHamel K: Living with metastatic breast cancer: A qualitative analysis of physical, psychological, and social sequelae. Breast J 19: 285-292, 2013.

3. Tanioka H, Omagari K, Kato Y, Nakata K, Kusumoto Y, Mori I, Furukawa R, Tajima H, Koga M, Yano M, et al: Present status of hepatitis virus-associated hepatocellular carcinoma in Nagasaki Prefecture, Japan: A cross-sectional study of 1019 patients. J Infect Chemother 8: 64-69, 2002.

4. Kim MJ, Lee M, Choi JY and Park YN: Imaging features of small hepatocellular carcinomas with microvascular invasion on gadoxetic acid-enhanced MR imaging. Eur J Radiol 81: 2507-2512, 2012

5. Karageorgos SA, Stratakou S, Koulentaki M, Voumvouraki A, Mantaka A, Samonakis D, Notas G and Kouroumalis EA: Long-term change in incidence and risk factors of cirrhosis and hepatocellular carcinoma in Crete, Greece: A 25-year study. Ann Gastroenterol 30: 357-363, 2017.

6. Davila JA, Morgan RO, Shaib Y, McGlynn KA and El-Serag HB: Hepatitis $\mathrm{C}$ infection and the increasing incidence of hepatocellular carcinoma: A population-based study. Gastroenterology 127: 1372-1380, 2004.

7. Ascha MS, Hanouneh IA, Lopez R, Tamimi TA, Feldstein AF and Zein NN: The incidence and risk factors of hepatocellular carcinoma in patients with nonalcoholic steatohepatitis. Hepatology 51: 1972-1978, 2010. 
8. Sersté T, Barrau V, Ozenne V, Vullierme MP, Bedossa P, Farges O, Valla DC, Vilgrain V, Paradis V and Degos F: Accuracy and disagreement of computed tomography and magnetic resonance imaging for the diagnosis of small hepatocellular carcinoma and dysplastic nodules: Role of biopsy. Hepatology 55: 800-806, 2012.

9. Sano K, Ichikawa T, Motosugi U, Sou H, Muhi AM, Matsuda M, Nakano M, Sakamoto M, Nakazawa T, Asakawa M, et al: Imaging study of early hepatocellular carcinoma: Usefulness of gadoxetic acid-enhanced MR imaging. Radiology 261: 834-844, 2011.

10. Yu MH, Kim JH, Yoon JH, Kim HC, Chung JW, Han JK and Choi BI: Small $(\leq 1-\mathrm{cm})$ hepatocellular carcinoma: Diagnostic performance and imaging features at gadoxetic acid-enhanced MR imaging. Radiology 271: 748-760, 2014.

11. Sheng RF, Zeng MS, Ji Y, Yang L, Chen CZ and Rao SX: MR features of small hepatocellular carcinoma in normal, fibrotic, and cirrhotic livers: A comparative study. Abdom Imaging 40: 3062-3069, 2015.

12. Kojiro M: Focus on dysplastic nodules and early hepatocellular carcinoma: An Eastern point of view. Liver Transpl 10 (Suppl 1): S3-S8, 2004.

13. Kojiro $\mathrm{M}$ and Roskams T: Early hepatocellular carcinoma and dysplastic nodules. Semin Liver Dis 25: 133-142, 2005.

14. Zhao H, Zhou KR and Yan FH: Role of multiphase scans by multirow-detector helical CT in detecting small hepatocellular carcinoma. World J Gastroenterol 9: 2198-2201, 2003.

15. Dale AM and Sereno MI: Improved localizadon of cortical activity by combining EEG and MEG with MRI cortical surface reconstruction: A linear approach. J Cogn Neurosci 5: 162-176, 1993.

16. Haimerl M, Wächtler M, Platzek I, Müller-Wille R, Niessen C, Hoffstetter P, Schreyer AG, Stroszczynski C and Wiggermann P: Added value of Gd-EOB-DTPA-enhanced hepatobiliary phase MR imaging in evaluation of focal solid hepatic lesions. BMC Med Imaging 13: 41, 2013.

17. Zhao W, Li W, Yi X, Pei Y, Liu H, Zhang L and Liu H: Diagnostic value of liver imaging reporting and data system MRI on primary hepatocellular carcinoma. Zhong Nan Da Xue Xue Bao Yi Xue Ban 41: 380-387, 2016 (In Chinese).

18. Palmucci S, Mauro LA, Messina M, Russo B, Failla G, Milone P, Berretta M and Ettorre GC: Diffusion-weighted MRI in a liver protocol: Its role in focal lesion detection. World J Radiol 4: 302-310, 2012.
19. Böttcher J, Hansch A, Pfeil A, Schmidt P, Malich A, Schneeweiss A, Maurer MH, Streitparth F, Teichgräber UK and Renz DM: Detection and classification of different liver lesions: Comparison of Gd-EOB-DTPA-enhanced MRI versus multiphasic spiral CT in a clinical single centre investigation. Eur J Radiol 82: 1860-1869, 2013.

20. Inoue $\mathrm{T}$, Hyodo $\mathrm{T}$, Murakami T, Takayama $\mathrm{Y}$, Nishie A, Higaki A, Korenaga K, Sakamoto A, Osaki Y, Aikata H, et al: Hypovascular hepatic nodules showing hypointense on the hepatobiliary-phase image of Gd-EOB-DTPA-enhanced MRI to develop a hypervascular hepatocellular carcinoma: A nationwide retrospective study on their natural course and risk factors. Dig Dis 31: 472-479, 2013

21. Macdonald GA and Peduto AJ: Magnetic resonance imaging (MRI) and diseases of the liver and biliary tract. Part 1. Basic principles, MRI in the assessment of diffuse and focal hepatic disease. J Gastroenterol Hepatol 15: 980-991, 2000.

22. Hwang J, Kim SH, Lee MW and Lee JY: Small ( $\leq 2 \mathrm{~cm})$ hepatocellular carcinoma in patients with chronic liver disease: Comparison of gadoxetic acid-enhanced 3.0 T MRI and multiphasic 64-multirow detector CT. Br J Radiol 85: e314-e322, 2012.

23. Park VY, Choi JY, Chung YE, Kim H, Park MS, Lim JS, Kim KW and Kim MJ: Dynamic enhancement pattern of HCC smaller than $3 \mathrm{~cm}$ in diameter on gadoxetic acid-enhanced MRI: Comparison with multiphasic MDCT. Liver Int 34: 1593-1602, 2014.

24. McNally ME, Martinez A, Khabiri H, Guy G, Michaels AJ, Hanje J, Kirkpatrick R, Bloomston $M$ and Schmidt CR: Inflammatory markers are associated with outcome in patients with unresectable hepatocellular carcinoma undergoing transarterial chemoembolization. Ann Surg Oncol 20: 923-928, 2013.

25. Lu DH, Fei ZL, Zhou JP, Hu ZT and Hao WS: A comparison between three-dimensional conformal radiotherapy combined with interventional treatment and interventional treatment alone for hepatocellular carcinoma with portal vein tumour thrombosis. J Med Imaging Radiat Oncol 59: 109-114, 2015.

This work is licensed under a Creative Commons Attribution-NonCommercial-NoDerivatives 4.0 International (CC BY-NC-ND 4.0) License. 